\title{
GENETIC DIVERSITY AND PHYLOGENETIC RELATIONSHIPS IN THE BAMBUSA GENUS AS REVEALED BY RAPD MARKERS
}

\author{
RONG, J. D. ${ }^{1}$ - ZHANG, Y. H. ${ }^{2}$ - FAN, L. L. ${ }^{1}-$ YU, Z. J. ${ }^{1}$ - CHEN, L. G. ${ }^{1}$ - TARIN, M. W. K. ${ }^{3}-$ \\ ZHANG, Z. X. ${ }^{1}-$ CHEN, L. Y. ${ }^{3}-$ ZHENG, Y. S. ${ }^{*}$ \\ ${ }^{I}$ College of Forestry, Fujian Agriculture and Forestry University, Fuzhou, Fujian 350002, PR \\ China
}

${ }^{2}$ Fujian Vocational College of Agriculture, Fuzhou, Fujian 350007, PR China

${ }^{3}$ College of Arts \& College of Landscape Architecture, Fujian Agriculture and Forestry University, Fuzhou, Fujian 350002, PR China

*Corresponding author

e-mail: zys1960@163.com; phone: +86-0591-8375-8750

(Received $5^{\text {th }}$ Feb 2020; accepted $22^{\text {nd }}$ May 2020)

\begin{abstract}
Understanding the genetic diversity and divergence within Bambusa has important implications for conservation and sustainable use. In this study, genetic diversity and phylogenetic relationships between 28 species/varieties of Bambusa were evaluated based on 16 randomly amplified polymorphic DNA (RAPD) primers screened from 96 primers. A total of 218 bands were amplified using these 16 primers, yielding DNA fragments of 290-3000 bp. The number of bands and percentage of polymorphism were 211 and $96.79 \%$, respectively, indicating high inter and intraspecific genetic diversity within Bambusa. In clustering analysis, genetic distances ranged from 0.2139 to 0.7647 . The 28 bamboo species/varieties were classified into six groups at a genetic distance of 0.6138 , consistent with traditional classification results. Our results indicated a high degree of polymorphism at RAPD loci, suggesting that the RAPD markers are effective for the analysis of genetic diversity and phylogenetic relationships in the genus. The results of this study provide a theoretical basis for germplasm conservation, classification, and evolutionary studies of Bambusa species/varieties.
\end{abstract}

Keywords: molecular diversity, genetic relationships, RAPD, bamboos

\section{Introduction}

The genus Bambusa, which belongs to the Bambusoideae subfamily, is highly abundant in China and has a wide range of applications. More than a hundred Bambusa species have been described and classified into three subgenera, i.e., Subgen Bambusa, Subgen Lingnania, and Subgen Leleba, with Bambusa chungii, Bambusa multiplex cv. Fernleaf, and Bambusa arundinacea as the respective type species. China, in particular, boasts approximately 60 Bambusa species, which are mainly distributed in the eastern, southern, and southwestern regions (Editorial Committee of Flora of China, Chinese Academy of Sciences, 1996; Zhu et al., 2017). Bambusa is characterized by sympodial rhizomes and has relatively high economic, aesthetic, and ecological value. Therefore, in-depth research on the genus is beneficial for the conservation of biodiversity within bamboo resources in China (Ma et al., 2007).

Although Bambusa species propagate by asexual reproduction, adaptations to different habitats and long-term evolution have resulted in genetic variation. The high genetic diversity in Bambusa poses certain challenges for the accurate differentiation and identification of Bambusa species (Lou et al., 2011). In addition, as bamboo species have low flowering and fruiting rates, the determination of interspecific relationships 
within Bambusa based on morphological markers, such as the morphological characteristics of flowers and fruits, or other markers, such as isozymes, is extremely difficult (Lin et al., 2008). Therefore, the quest for effective markers has become a key topic in phylogenetic studies of Bambusa.

Advances in molecular biology have substantially improved DNA marker techniques, enabling the direct comparison of genetic material without the influence of external environmental factors (Liu et al., 2015). Such techniques are increasingly used for analyses of genetic diversity and phylogenetic relationships within Bambusa. Randomly amplified polymorphic DNA (RAPD) marker detection, using electrophoresis and PCR (Mutharaian et al., 2018), has several advantages, such as its high sensitivity, low cost, and ease, enabling the acquisition of large quantities of information (Xia et al., 2001); accordingly, this approach is widely used for studies of genetic diversity (He et al., 2019; Tanzeem et al., 2019; Leandro et al.2019; Subramanyam et al., 2010), phylogenetic relationships (Amom et al., 2020; Liu et al., 2016), variety identification (Odunayo et al., 2019; Archana et al., 2013), and DNA fingerprinting (Mei et al., 2014; Afshari et al., 2016). However, few studies have utilized RAPD to evaluate Bambusa. In this study, 28 Bambusa species/varieties were used as test materials for a RAPD-based analysis of genetic diversity and phylogenetic relationships to provide a theoretical basis for germplasm conservation, classification, and evolutionary studies of Bambusa species/varieties.

\section{Materials and methods}

\section{Test materials}

The test materials were obtained from 28 Bambusa species/varieties from the Bamboo Cultivation Base of the Fujian Agriculture and Forestry University, Fuzhou, China in August 2018. Table 1 provides basic information for the test materials. Fresh uninfested leaves (3-6 g) were harvested from each plant and stored in a $-80{ }^{\circ} \mathrm{C}$ ultralow temperature freezer until genomic DNA extraction.

\section{Methods}

\section{DNA extraction and detection}

Genomic DNA was extracted using the CTAB method (Zhang et al., 2014), and the concentration was measured using a NANODROP 2000 spectrophotometer. Electrophoresis was performed using a $1.0 \%$ agarose gel; briefly, $9 \mu \mathrm{L}$ of template DNA was mixed with $1.5 \mu \mathrm{L}$ of $6 \times$ loading buffer and subjected to $120 \mathrm{~V}\left(5 \mathrm{~V} \cdot \mathrm{cm}^{-2}\right)$ for $30 \mathrm{~min}$, using $1 \times \mathrm{TBE}$ as the electrophoresis buffer. The electrophoresis results were analyzed using a gel imaging system. The size of the DNA ladder marker (No. B500347, Sangon Biotech) is $100-3000 \mathrm{bp}$. Total DNA that satisfied the study requirements was diluted to a $20 \mathrm{ng} \cdot \mu \mathrm{L}^{-1}$ and stored in a $-20{ }^{\circ} \mathrm{C}$ freezer before further use.

\section{Primer screening}

A total of 96 random oligonucleotide primers of $10 \mathrm{bp}$ were purchased from Sangon Biotech Co., Ltd. (Shanghai, China) and used for the preamplification of the total DNA of certain Bambusa species/varieties. Then, 16 primers that produced bands with high 
clarity, stability, degree of polymorphism, and reproducibility were selected for the RAPD analysis with the total DNA of all 28 bamboo species/varieties. Table 2 shows a list of selected primers and sequences.

Table 1. Summary of test materials

\begin{tabular}{c|c}
\hline No. & Species/variety name \\
\hline 1 & Bambusa sinospinosa \\
2 & B. rutila \\
3 & B. subaequalis \\
4 & B. gibba \\
5 & B. ventricosa \\
6 & B. remotiflora \\
7 & B. cerosisssima \\
8 & B. textilis cv. Maculata \\
9 & B. textilis var. gracilis \\
10 & B. tulda \\
11 & B. pervariabilis \\
12 & B. longispiculata \\
13 & B. tuloides \\
14 & B. subtruncata \\
15 & B. boniopsis \\
16 & B. vulgaris \\
17 & B. vulgaris cv. Vittata \\
18 & B. vulgaris cv. Wamin \\
19 & B. gibboides \\
20 & B. albo-lineata \\
21 & B. lenta \\
22 & B. contracta \\
23 & B. multiplex \\
24 & B. multiplex cv. Silverstripe \\
25 & B. multiplex cv. Fernleaf \\
26 & Bultiplex var. riviereorum \\
27 & \\
28 & \\
\hline
\end{tabular}

Table 2. List of primers and sequences

\begin{tabular}{c|c|c|c}
\hline Primer & $\begin{array}{c}\text { Sequence } \\
\mathbf{5}^{\prime}-\mathbf{3}^{\prime}\end{array}$ & Primer & $\begin{array}{c}\text { Sequence } \\
\mathbf{5}^{\prime}-\mathbf{3}^{\prime}\end{array}$ \\
\hline S4 & GGACTGGAGT & S69 & CTCACCGTCC \\
S5 & TGCGCCCTTC & S431 & TCGCCGCAAA \\
S13 & TTCCCCCGCT & S1219 & CTGATCGCGG \\
S26 & GGTCCCTGAC & S2093 & TCGGTGAGTC \\
S32 & TCGGCGATAG & S1408 & GTTACGGACC \\
S36 & AGCCAGCGAA & S1412 & CCTGTACCGA \\
S45 & TGAGCGGACA & S1420 & CTTCTCGGAC \\
S67 & GTCCCGACGA & S1421 & TCCCAGCAGA \\
\hline
\end{tabular}




\section{RAPD-PCR and the detection of amplification products}

PCR was performed using a LabCycler PCR System (SensoQuest International Ltd). The reaction system for RAPD-PCR consisted of the following: $2.0 \mu \mathrm{L}$ of $10 \times$ buffer, $3.5 \mathrm{mmol} \cdot \mathrm{L}^{-1} \mathrm{Mg}^{2+}, 0.4 \mathrm{mmol} \cdot \mathrm{L}^{-1} \mathrm{dNTPs}, 0.6 \mu \mathrm{mol} \cdot \mathrm{L}^{-1}$ primer, $3.0 \mathrm{U}$ of $\mathrm{Taq}$ polymerase, $40 \mathrm{ng}$ of template DNA, and sterile $\mathrm{ddH}_{2} \mathrm{O}$ for a total volume of $20 \mu \mathrm{L}$.

The RAPD-PCR protocol was as follows: initial denaturation at $94{ }^{\circ} \mathrm{C}$ for $2 \mathrm{~min}$, denaturation at $94^{\circ} \mathrm{C}$ for $30 \mathrm{~s}$, annealing at $34^{\circ} \mathrm{C}$ for $30 \mathrm{~s}$, and extension at $70{ }^{\circ} \mathrm{C}$ for $90 \mathrm{~s}$ for 38 cycles; final extension at $72^{\circ} \mathrm{C}$ for $7 \mathrm{~min}$. The PCR products were stored in a $4{ }^{\circ} \mathrm{C}$ refrigerator, and detection was subsequently performed by electrophoresis on a $1.0 \%$ agarose gel.

\section{Statistical analysis}

POPGENE version 3.2 was used to determine the total number of bands and the number of polymorphic bands amplified by each primer (Yeh et al., 1999). The bands produced at the same site by different primers were counted for each sample, assigning a value of 1 if a band was present and 0 if a band was absent. DPS 18.10 was used to analyze genetic diversity, perform a clustering analysis, and construct a phylogenetic tree of the tested Bambusa species/varieties (Tang et al., 2013).

\section{Results and analysis}

\section{Analysis of RAPD marker polymorphism}

Among 96 random RAPD primers used for preamplification, 16 primers produced bands with high clarity, degree of polymorphism, and stability and were selected for marker amplification from all 28 Bambusa species/varieties. Figures 1 and 2 show the representative gel electrophoresis results obtained with primers S32 and S431. In total, 218 clear bands were obtained with the 16 primers, and 211 of these bands were polymorphic. On average, 13.63 bands and 13.19 polymorphic bands were obtained for each primer. The percentages of polymorphism for the primers ranged from $77.78 \%$ to $100 \%$ and the average percentage was $96.79 \%$ (Table 3). Each primer produced 621 bands and 5-21 polymorphic bands, with fragment lengths of 190-3000 bp. These results indicate that genetic diversity is high within Bambusa. This high diversity suggests that the genus possesses a strong ability to adapt to various environments. Furthermore, interspecific genetic differences within Bambusa can be effectively elucidated by RAPD markers.

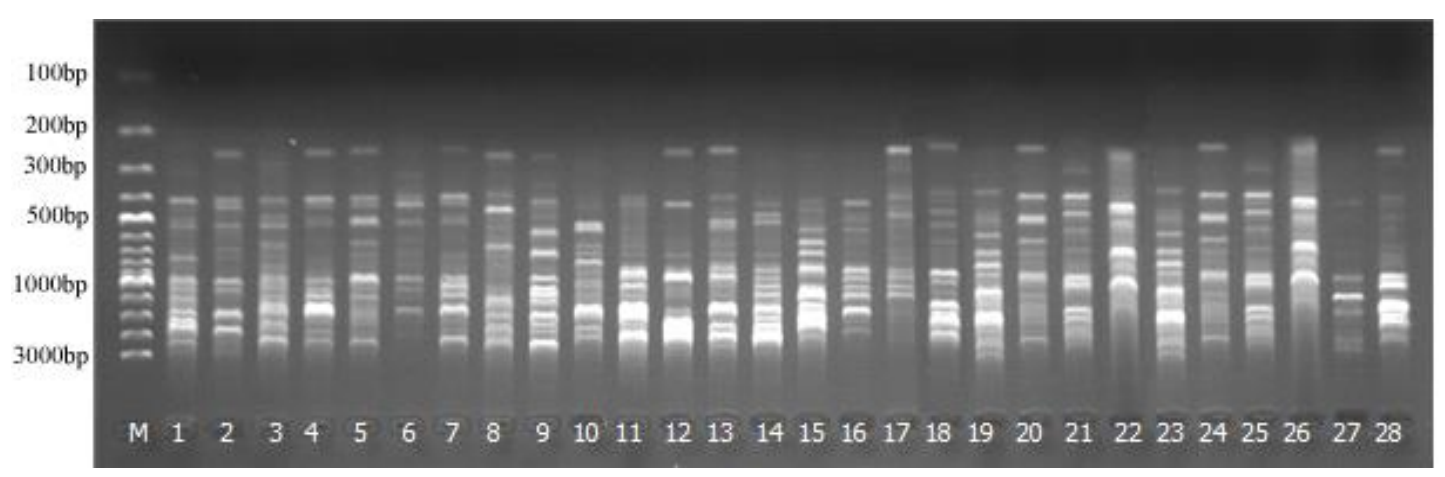

Figure 1. Electrophoresis results for 28 Bambusa samples amplified using RAPD S32 


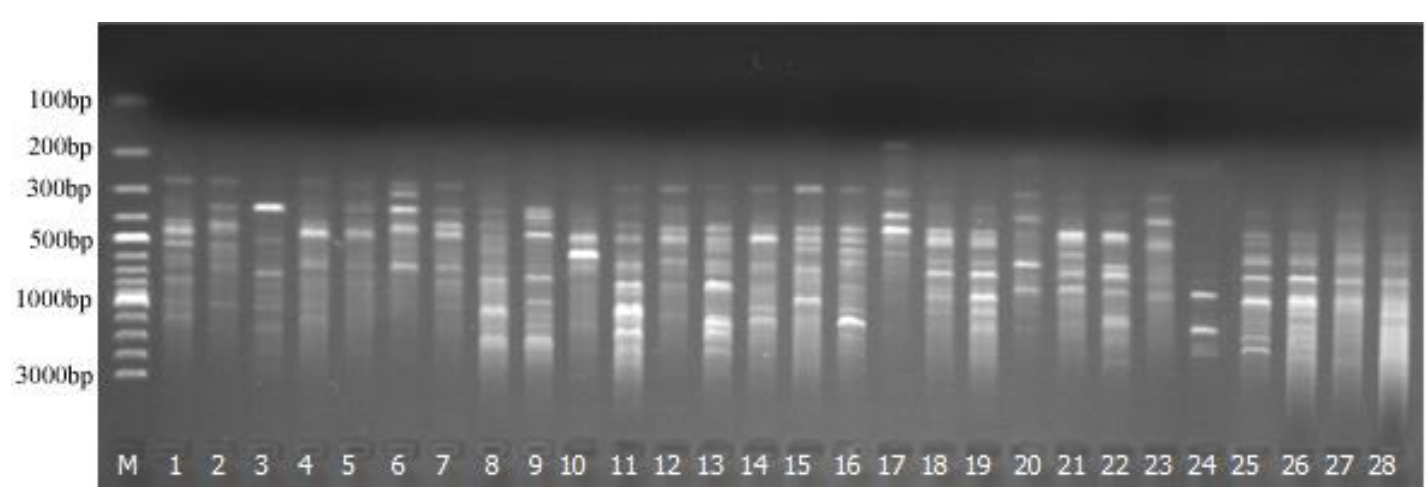

Figure 2. Electrophoresis results for 28 Bambusa samples amplified using RAPD S431

Table 3. RAPD primers and percentages of polymorphism

\begin{tabular}{c|c|c|c}
\hline Primer & Total no. of bands & No. of polymorphic bands & Percentage of polymorphism (\%) \\
\hline S4 & 14 & 14 & 100 \\
S5 & 12 & 12 & 100 \\
S13 & 17 & 17 & 100 \\
S26 & 10 & 9 & 90.00 \\
S32 & 21 & 21 & 100 \\
S36 & 9 & 7 & 77.78 \\
S45 & 6 & 5 & 83.33 \\
S67 & 13 & 12 & 92.31 \\
S69 & 13 & 13 & 100 \\
S431 & 15 & 15 & 100 \\
S1219 & 12 & 11 & 91.67 \\
S2093 & 13 & 13 & 100 \\
S1408 & 14 & 13 & 92.86 \\
S1412 & 15 & 15 & 100 \\
S1420 & 17 & 17 & 100 \\
S1421 & 17 & 17 & 100 \\
Total & 218 & 211 & 96.79 \\
Average & 13.63 & 13.19 & 96.79 \\
\hline
\end{tabular}

\section{Analysis of genetic distances and genetic diversity among the Bambusa species/varieties}

For the 16 primers, a data matrix was generated from the genomic fingerprint, and pairwise genetic distances among the various Bambusa species/varieties were calculated using DPS 18.10 based on Jaccard's formula (Yhang et al., 2010) (Table 4). The average genetic distance was 0.5597 and the range was $0.2139-0.7647$, indicating a relatively high average and a high degree of variation. As shown in Table 4, the genetic distances within the genus Bambusa were mostly around 0.5, indicating good genetic stability. The genetic distances between variants or cultivars of the same species were lower than those for comparisons between different species. For instance, the genetic distances among B. multiplex cv. Alphonse-Karr, B. multiplex cv. Silverstripe, B. multiplex cv. Fernleaf, and B. multiplex var. riviereorum, belonging to Bambusa 
subgen. Leleba, were relatively low, while the genetic distance between B. subaequalis (belonging to Bambusa subgen. Bambusa) and B. subtruncata (belonging to Bambusa subgen. Leleba) was high. These results demonstrate that the phylogenetic relationships among Bambusa species/varieties are consistent with the morphological classification and that RAPD markers are effective indicators of genetic diversity in Bambusa species/varieties.

Table 4. The genetic distance matrix for 28 Bambusa species/varieties

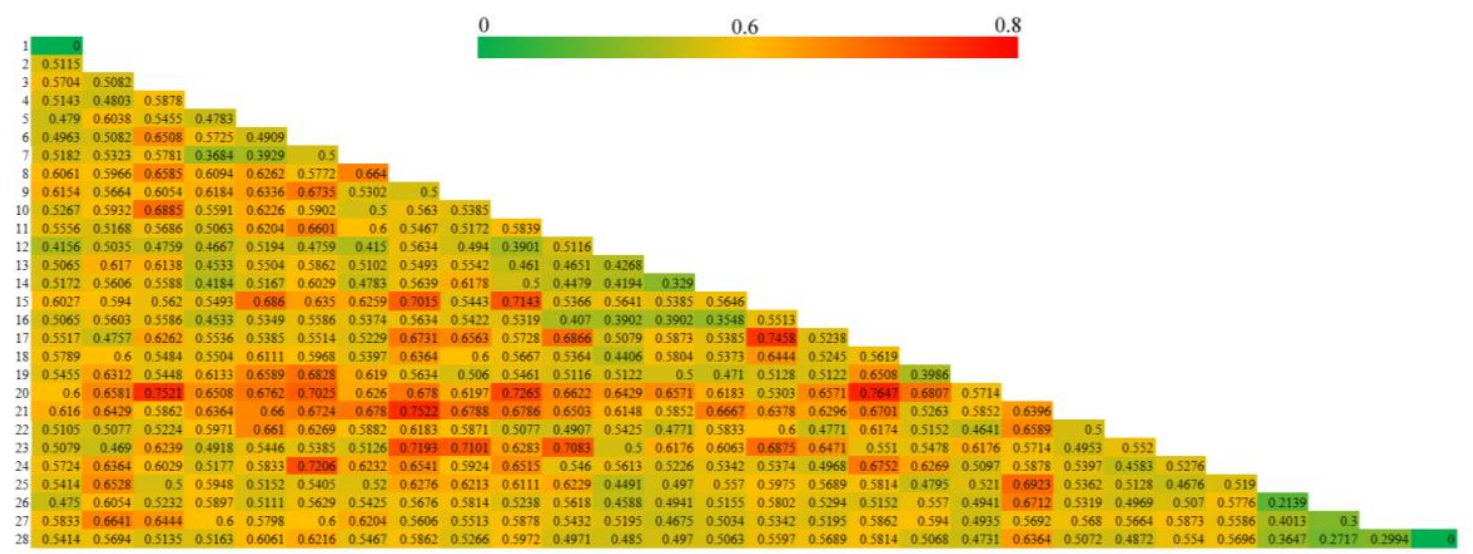

\section{Cluster analysis of Bambusa species/varieties}

Based on the RAPD-PCR amplification results, phylogenetic relationships within Bambusa were analyzed with the raw genotypic data matrix using DPS 18.10 (Tang et al., 2013). A cluster analysis was performed based on genetic distances using the NeiLi maximum distance method (Zaya et al., 2017), and a dendrogram was constructed (Fig. 3; Table 5). The clustering results indicate that the 28 Bambusa species/varieties could be classified into six groups at a genetic distance of 0.57 (L1). (1) Group 1 (genetic distance $=0.6038$ ) included 8 species/varieties $(B$. sinospinosa, $B$. remotiflora, B. rutila, B. contracta, B. vulgaris, B. gibba, B. cerosisssima, and B. ventricosa); Group 2 (genetic distance $=0.5634)$ included 4 species/varieties $(B$. textilis cv. Maculata, $B$. textilis var. gracilis, B. tulda, and B. pervariabilis); (3) Group 3 (genetic distance $=0.5484$ ) included 3 species/varieties (B. subaequalis, B. vulgaris cv. Vittata, and $B$. vulgaris cv. Wamin); (4) Group 4 (genetic distance $=0.4651$ ) included 4 species/varieties (B. eutuldoides McClure var. viridi-vittata, B. longispiculata, B. tuloides, and B. boniopsis); (5) Group 5 (genetic distance $=0.5776$ ) included 7 species/varieties (B. albo-lineata, B. lenta, B. multiplex, B. multiplex cv. Alphonse-Karr, B. multiplex cv. Silverstripe, B. multiplex cv. Fernleaf, B. multiplex var. riviereorum); (6) Group 6 (genetic distance $=0.5303$ ) included 2 species/varieties (B. subtruncata and B. gibboides).

Groups 1 and 2 exhibited a genetic distance of 0.7193 , with $B$. sinospinosa, B. rutila, $B$. gibba, and B. ventricosa (all belonging to Bambusa subgen. Bambusa) forming a distinct cluster, and B. remotiflora, B. cerosisssima, B. textilis cv. Maculata, and B. textilis var. gracilis (all belonging to Bambusa subgen. Lingnania) clustering together. However, B. subaequalis, which belongs to Bambusa subgen. Bambusa, did not cluster with species in the same subgenus; instead, it formed a group with the majority of members of Bambusa subgen. Leleba, as evidenced by the shorter genetic distances. In 
Group 3, B. vulgaris cv. Vittata and B. vulgaris cv. Wamin, which are both members of Bambusa subgen. Leleba and variants of B. vulgaris, did not cluster together with $B$. vulgaris; instead, they formed a cluster with B. subaequalis of Bambusa subgen. Bambusa (genetic distance, 0.5484). In Group 5, B. multiplex was distinctly clustered with its cultivated variants $B$. multiplex cv. Alphonse-Karr, B. multiplex cv. Silverstripe, $B$. multiplex cv. Fernleaf, and B. multiplex var. riviereorum, consistent with traditional classification results. However, B. multiplex cv. Alphonse-Karr, B. multiplex cv. Silverstripe, B. multiplex cv. Fernleaf, and B. multiplex var. riviereorum did not clustered together with $B$. multiplex; instead, they clustered together with $B$. multiplex, $B$. lenta, and $B$. albo-lineata (genetic distance, 0.5776). This indicates that divergence in B. multiplex resulted in greater genetic similarity with B. lenta and B. albo-lineata.

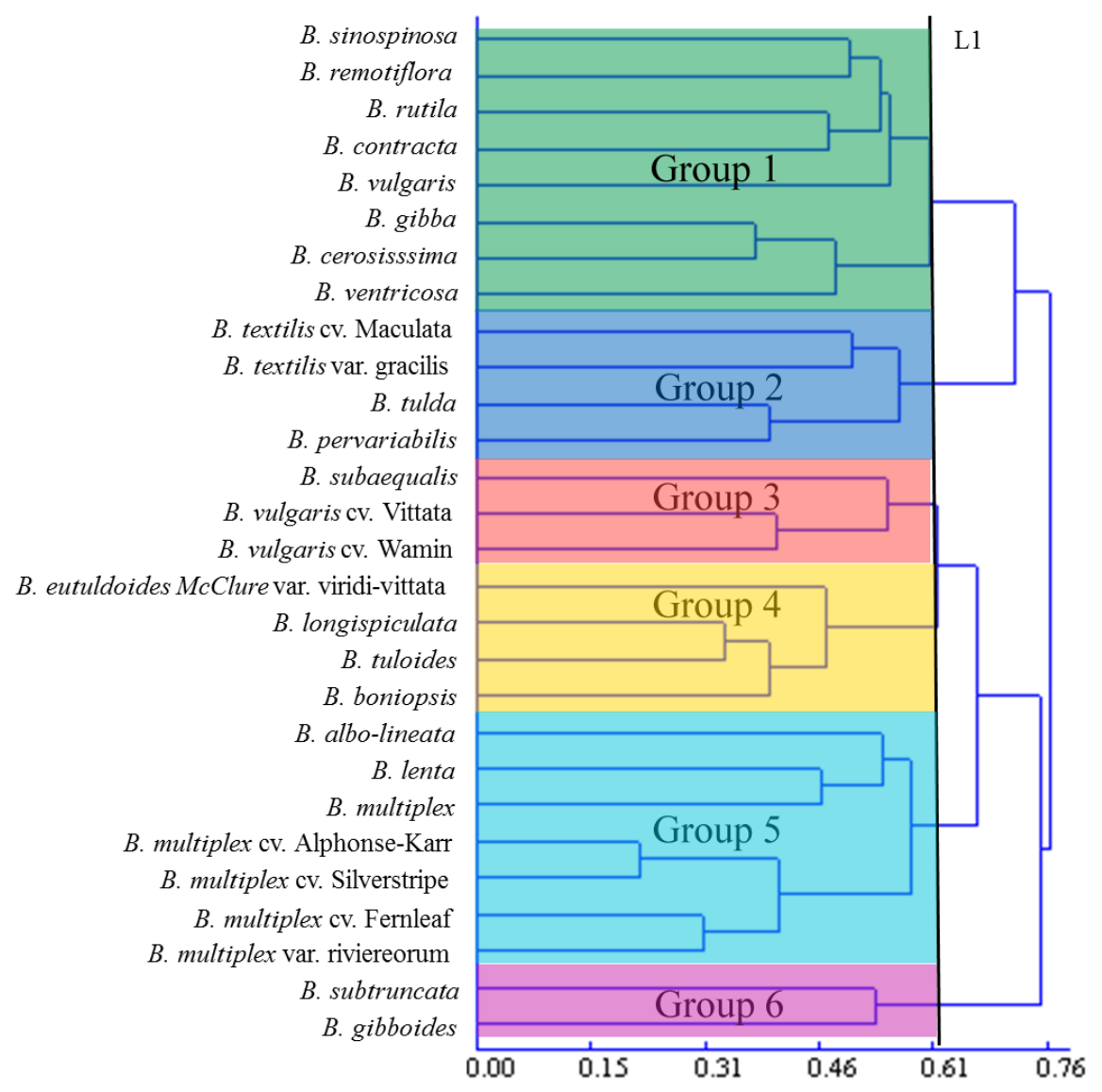

Figure 3. Dendrogram of the 28 Bambusa species/varieties based on RAPD markers

\section{Discussion}

Previous research has demonstrated that the main determinants of the stability and reproducibility of RAPD analyses are temperature conditions, reagent concentrations, and the duration of various PCR steps (Bi et al., 2011). The application of the RAPD method for the investigation of interspecific relationships (including subspecific classes) within Bambusa is rare, with a literature search yielding a single study by Nayak et al (2003) involving only a few Bambusa species. In this study, we adopted the RAPD technique for the analysis of genetic differences and phylogenetic relationships among 28 Bambusa species/varieties. The amplification patterns of certain primers consisted of 
a variety of bands with significant differences. Amplification using 16 primers produced 218 clear bands, with $96.79 \%$ (211 bands) polymorphism. Therefore, a high level of polymorphism within Bambusa was detected with RAPD molecular markers, demonstrating that the approach is practical and effective for genetic analyses of the genus.

Table 5. Clustering and genetic distances of the 28 Bambusa species/varieties

\begin{tabular}{c|c|c|c}
\hline $\begin{array}{c}\text { T } \\
\text { Number }\end{array}$ & $\begin{array}{c}\text { I } \\
\text { Linked level }\end{array}$ & $\begin{array}{c}\text { J } \\
\text { Indexing of clustering order }\end{array}$ & Distance \\
\hline 1 & 26 & 25 & 0.2139 \\
2 & 28 & 27 & 0.2994 \\
3 & 14 & 13 & 0.3290 \\
4 & 7 & 4 & 0.3684 \\
5 & 12 & 10 & 0.3901 \\
6 & 16 & 13 & 0.3902 \\
7 & 19 & 18 & 0.3986 \\
8 & 27 & 25 & 0.4013 \\
9 & 24 & 22 & 0.4583 \\
10 & 13 & 11 & 0.4651 \\
11 & 23 & 2 & 0.4690 \\
12 & 5 & 4 & 0.4783 \\
13 & 6 & 1 & 0.4963 \\
14 & 9 & 8 & 0.5000 \\
15 & 20 & 15 & 0.5303 \\
16 & 2 & 1 & 0.5385 \\
17 & 22 & 21 & 0.5397 \\
18 & 18 & 3 & 0.5484 \\
19 & 17 & 1 & 0.5517 \\
20 & 10 & 8 & 0.5634 \\
21 & 25 & 21 & 0.5776 \\
22 & 1 & 0.6038 \\
23 & 11 & 3 & 0.6138 \\
24 & 21 & 3 & 0.6667 \\
25 & 8 & 1 & 0.7193 \\
26 & & 3 & 0.7521 \\
27 & 15 & 0.7647 \\
\hline & & & \\
\hline
\end{tabular}

The average genetic distance range of values were high. These results show that Bambusa possesses high genetic diversity and relatively complex interspecific genetic relationships (Zhan et al., 2015). The genus is highly influenced by various factors, such as geographical location, climate fluctuations, and various evolutionary processes (Lou et al., 2011), leading to the establishment of a diverse gene pool.

A clustering analysis based on RAPD markers showed that the 28 Bambusa species/varieties could be clearly distinguished. The species/varieties were classified into 6 groups, consistent with results based on morphological properties. Compared with Nayak et al. (2003), a larger number of primers and samples were used in this study. However, the results of the two studies were largely consistent and in agreement 
with Loh et al. (2000), who adopted amplified fragment length polymorphism (AFLP) markers for the analysis of genetic diversity and relationships. In Group 3, B. vulgaris cv. Vittata and B. vulgaris cv. Wamin, both members of Bambusa subgen. Leleba and variants of $B$. vulgaris, were not initially clustered with $B$. vulgaris; instead, they were clustered with $B$. subaequalis of Bambusa subgen. Bambusa and only formed a cluster with $B$. vulgaris at a genetic distance of 0.7647 . This can be explained by variation in $B$. vulgaris cv. Vittata and B. vulgaris cv. Wamin or anthropomorphic disturbance; further research is required to determine the exact cause. In Group 5, except for B. albo-lineata, the genetic distances among other species/varieties were less than 0.5, indicating that genetic traits within the group were relatively stable. All species/varieties within this group belong to Bambusa subgen. Leleba according to the traditional classification described in the Flora of China. In particular, B. multiplex cv. Alphonse-Karr and B. multiplex cv. Silverstripe, which are both cultivated varieties of B. multiplex, exhibited high genetic similarity. Sun et al. (Sun et al., 2005) utilized ribosomal DNA ITS sequences in a study of $B$. subaequalis and B. multiplex $\mathrm{cv}$. Fernleaf, and suggested that the two species are sister species. Based on the results of the present study, $B$. subaequalis and B. multiplex cv. Fernleaf are closely related, further supporting the sister-group relationship.

\section{Conclusions}

Genetic diversity and phylogenetic relationships within Bambusa can be reliable and reproducibly evaluated based on RAPD markers. The 28 tested Bambusa species/varieties possess high genetic diversity and complex phylogenetic relationships. When combined with morphological features, the results of this study can provide a theoretical basis for germplasm conservation, classification, and evolutionary analyses of Bambusa species/varieties. It is obligatory to fortify the collection, identification, and excavation of the germplasm resources of Bambusa to augment the genetic diversity of breeding materials. Continuous development of biotechnology, in bamboo research will be required to address more problems. Bamboo genome research, gene mechanism, transgenic technology, and cloning technology can be a new direction in bamboo research.

Acknowledgments. This work was supported by Science and Technology Major Projects of Fujian Province [2013NZ0001], Fujian Agriculture and Forestry University Science and Technology Development Fund Project [KF2015085]. The author thanks anonymous reviewers who provided helpful suggestions and critical comments on this manuscript.

\section{REFERENCES}

[1] Afshari, A., Jamshidi, A., Razmyar, J. (2016): Genomic diversity of Clostridium perfringens strains isolated from food and human sources. - Iranian Journal of Veterinary Research 17: 160-164.

[2] Amom, T., Tikendra, L., Apana, N., Goutam, M., Sonia, P., Koijam Arunkumar, S., Potshangbam, A., Rahaman, H., Nongdam, P. (2020): Efficiency of RAPD, ISSR, iPBS, SCoT and phytochemical markers in the genetic relationship study of five native and economical important bamboos of North-East India. - Phytochemistry. https://doi.org/10.1016/j.phytochem.2020.112330. 
[3] Archana, C. P., Deepu, V., Geetha, S. P., Indira, B. (2013): RAPD assessment for identification of clonal fidelity of microrhizome induced plants of Turmeric (Curcuma longa L.) cultivars. - International Food Research Journal 20: 3325-3328.

[4] Bi, Y., Du, X., Zhong, Z. (2011): Advances in the application of biological techniques in Bambusa. - Journal of Bamboo Research 30: 57-62.

[5] Editorial Committee of flora of China, Chinese Academy of Sciences (1996): Flora of China: Vol. 9, Vol. 1. - Science Press, Beijing, pp. 48-49.

[6] He, T. Y., Qu, Y. Q., Chen, L. Y., Xu, W., Rong, J. D., Chen, L. G., Fan, L. L., Tarin, M. W. K., Zheng, Y. S., (2019): Genetic diversity analysis of Dendrocalamopsis beecheyana var. Pubescens based on ISSR markers. - Appl. Ecol. Environ. Res. 17: 12507-12518.

[7] Leandro, P., Santiago, V., Ana, F., Jaime, P., Adrián, R. (2019): Genetic diversity, population structure, and relationships in a collection of pepper (Capsicum spp.) landraces from the Spanish Centre of Diversity revealed by genotyping-by-sequencing (GBS). - Horticulture Research. DOI: 10.1038/s41438-019-0132-8.

[8] Lin, S., Ding, Y., Zhang, H. (2008): Pollen germination percentage and the floral character of five bamboo species. - Scientia Silvae Sinicae 44: 159-163.

[9] Liu, D., Yang, L., Fang, Z., Liu, Y., Zhuang, M., Zhang, Y., Li, Z., Lyu, H. (2015): Progress of Brassica crops molecular breeding. - Journal of Agricultural Science and Technology 17: 15-22.

[10] Liu, S., Wang, X., Jiang, C., Yuan, W., Zhang, J. (2016): RAPD-PCR analysis on different germplasm resources of Curcumae Rhizoma. - Chinese Traditional and Herbal Drugs 47: 3098-3102.

[11] Loh, J. P., Kiew, R., Set, O., Gan, L. H., Gan, Y. Y. (2000): A study of genetic variation and relationships within the bamboo subtribe Bambusinae using amplified fragment length polymorphism. - Annals of Botany (London) 85: 607-612.

[12] Lou, Y., Yang, H., Zhang, Y., Li, X., Lin, X., Fang, W. (2011): Analysis of genetic variation of some bamboo species by AFLP, ISSR and SRAP. - Journal of Fujian College of Forestry 31: 38-43.

[13] Ma, N., Chen, G., Yuan, J. (2007): Bamboo biodiversity and conservation strategies in China. - Scientia Silvae Sinicae 43: 105-109.

[14] Mei, Z., Md, A., Zeng, W., unjiang Fu, J. (2014): DNA fingerprints of living fossil Ginkgo biloba by using ISSR and improved RAPD analysis. - Biochemical Systematics and Ecology 36: 98-103.

[15] Mutharaian, V. N., Kamalakannan, R., Mayavel, A., Makesh, S., Kwon, H., Kang, K. (2018): DNA polymorphisms and genetic relationship among populations of Acacia leucophloea using RAPD markers. - Journal of Forestry Research 29: 1-8.

[16] Nayak, S., Rout, G. R., Das, P. (2003): Evaluation of genetic variability in bamboo using rapd markers. - Plant Soil and Environment 49: 24-28.

[17] Odunayo, J., Abeeb, A. (2019): Molecular evaluation of Garcinia kola Heckel accessions using RAPD markers. - American Journal of Molecular Biology 9: 41-51.

[18] Subramanyam, Rao, D., Devanna, N., Aravinda, A. (2010): Evaluation of genetic diversity among Jatropha curcas (L) by RAPD analysis. - Indian Journal of Biotechnology 9: 283-288.

[19] Sun, Y., Xia, N., Lin, R. (2005): Phylogenetic analysis of Bambusa (Poaceae: Bambusoideae) based on internal transcribed spacer sequences of nuclear ribosomal DNA. - Biochemical Genetics 43: 603-612.

[20] Tang, Q., Zhang, C. (2013): Data Processing System (DPS) software with experimental design, statistical analysis and data mining developed for use in entomological research. Insect Science 20: 254-260.

[21] Tanzeem, F., Ashutosh, S., Vageeshbabu, S., Somashekar, P., Srinivasa Rao, M. (2019): Genetic diversity estimates of Santalum album L. through microsatellite markers: implications on conservation. - American Journal of Plant Science 10: 462-485. 
[22] Xia, M., Zhou, X., Zhao, S. (2001): RAPD analysis on genetic diversity of natural populations of Pinus koraiensis. - Acta Ecologica Sinica 21: 730-737.

[23] Yang, R., Sun, Z., Xiang, Y. (2010): SSR analysis of genetic diversity among 14 bamboo species in Phyllostachys. - Journal of Bamboo Research 29: 11-14, 20.

[24] Yeh, F. C., Yang, R. (1999): Microsoft Window-Based Freeware for Population Genetic Analysis (POPGENE Ver. 1.31). - University of Alberta, Alberta.

[25] Zaya, D. N., Molano-Flores, B., Feist, M. A., Koontz, J. A., Coons, J. (2017): Assessing genetic diversity for the USA endemic carnivorous plant Pinguicula ionantha R. K. Godfrey (Lentibulariaceae). - Conservation Genetics 18: 171-180.

[26] Zhan, M., Yang, Y., Cheng, Z., Su, G., Hu, W., Chen, H., Huang, Q. (2015): Genetic diversity of olive varieties based on SRAP markers. - Scientia Silvae Sinicae 51: 157164.

[27] Zhang, Y., Shi, M., De, J., Suo, N., La, D. (2014): Extraction of genomic DNA from Chenopodium foetidum and detection of its RAPD. - Journal of Tibet University 29: 1316.

[28] Zhu, Z., Cai, H., Bi, S., Zhong, Z., Du, X. (2017): A study on the examination guideline of distinctness, uniformity and stability of Bambusa. - Journal of Bamboo Research 36: $44-48,65$. 